\title{
Platonism and Forms of Life
}

\author{
RICHARD M. GASKIN \\ St. Edmund Hall, Oxford
}

There is a longstanding tradition in philosophical reflection which attempts to draw a sharp metaphysical and epistemological distinction between the self and the world. Metaphysically, the self is regarded as an entity quite unlike anything to be met with in the world; it is, in some sense, outside or transcendental with respect to the world. Epistemologically, the knowing self is conceived as a locus of pure thought, set over against the empirical world, and engaging with it in an entirely passive way. On this picture, no characteristic or activity of the self constitutes the world which impinges on its cognitive faculties; its inert and lusterless mind simply mirrors, or represents, a rich and active world. It is natural to regard this view as a version of realism. Something like this realism seems to have been espoused by the early Wittgenstein; but in his later writings we encounter a doctrine which is clearly meant to oppose it. This opposing position holds that there is a constitutive connection between thought on the one hand and empirical reality--in particular social facts and language-on the other. The notion of a form of life is what unites the twin elements of social facts and language, which Wittgenstein aims to deploy as a grounding for thought. For a form of life is clearly a social phenomenon; and it also performs a function for Wittgenstein as the unique correlate of something linguistic-namely grammar. ${ }^{1}$ The idea is that a form of life, in its social and grammatical realizations, should supplant the realist's dichotomy between mirroring thought and readymade world. I shall argue that it cannot in fact discharge this role, adducing support for this claim in the context of an elucidation of what Wittgenstein's doctrine, when properly set out, must look like. I shall restrict myself to what is arguably the test case for the doctrine-certainly the case Wittgenstein himself concentrates on most heavily-namely that of logical and simple arithmetical necessity. We shall consequently be concerned with the form of realism which ordinarily goes under the name of platonism.

On P.226 of PI Wittgenstein writes: 'What has to be accepted, the given, is-so one could say-forms of life.' This characterization of forms of

${ }^{1}$ Cf. Philosophical Investigations (Oxford: Blackwell, 1958), hereafter PI, 1.19. I shall also use the following abbreviations for the works of Wittgenstein: $R F M=$ Remarks On the Foundations Of Mathematics, Third Edition (Oxford: Blackwell, 1978); $O C=$ On Certainty (Oxford: Blackwell, 1979); $Z$ = Zettel (Oxford: Blackwell, 1981). 
life as 'given' is suggestive of an illuminating connection with the 'given' of the empiricists. In their case, the phenomenal 'given' grounds perceptual knowledge, either explicitly--we consciously construct a conceptualized spatial reality from given unconceptualized bits of bare phenomenologyor implicitly, in which case the feat of organizing the 'given' has been achieved by the time the subject has been constituted as a self-conscious experiencer of an objective reality. Now neither of these accounts describes a process which we can actually observe going on. This is fatal to the credibility of the first account, because it purports to tell just such a story. The second account, however, is attemptirg to begin on an answer to the question: how is it possible for a subject to experience an objective reality? The question is not meant to be an empirical one, but a peculiarly philosophical one; the answer takes the form of a transcendental deduction of the necessary conditions of experience. The 'given' then enters the picture as the necessary raw material on which the transcendental mind gets to work, producing the possibility of perceiving an objective world. It is part of the transcendental foundation of the empirical world we inhabit.

The parallel with Wittgenstein is then this: we might say that the existence of a form of life is transcendentally deduced as a necessary grounding of meaning (in general, normativity), and hence truth (truth attaches to meaning-bearers, i.e., propositions). Hence also, via the internal connection between truth and the world, the existence of a form of life is deduced as the basis of our possession of a world. We might cast the question which the notion of a form of life is equipping us to answer as: how is it possible for human beings (or anyone) to measure (say)? The answer comes back: a certain agreement in judgments (a common form of life) is necessary (PI 1.241). Wittgenstein is careful to deny that such agreement suffices for truth, but he nevertheless wants a sense in which it is a necessary enabling condition of truth. Like Kant's 'given', it is a transcendentally deduced grounding for the activity (normativity) which underwrites the possibility of meaningful language, and hence (via the connection between meaning and truth) which guarantees our possession of the world.

Wittgenstein's desire here to avoid falling into a naive relativism emerges in several places: one particularly striking one is PI Il.xii. Here he seems to try to distinguish the transcendental thesis he has in his sights from an empirical answer to the question 'how is it possible...?'

If the formation of concepts can be explained by facts of nature, should we not be interested, not in grammar, but rather in that in nature which is the basis of grammar?-Our interest certainly includes the correspondence between concepts and very general facts of nature...But...we are not doing natural science; nor yet natural history...I am not saying: if such-and-such facts of nature were 
different people would have different concepts (in the sense of a hypothesis). But: if anyone believes that certain concepts are absolutely the correct ones, and that having different ones would mean not realizing something that we realize--then let him imagine certain very general facts of nature to be different from what we are used to, and the formation of concepts different from the usual ones will become intelligible to him.

Wittgenstein here refuses to say that those who have a different form of life embodying different concepts 'would not realize something that we realize.' There is no truth of the matter transcending form of life: truth is located within a form of life. But there is apparently no naive conventionalism about truth here. Truth does not consist in what the livers of a form of life say is true (RFM VI.49). But agreement in judgment, which may be--perhaps must be-operative at an implicit level $(Z 430)$, is necessary to constitute an institution (form of life, grammar) in which meaning, and hence truth and falsity, are possible.

Wittgenstein claims to have no desire to shake our confidence in the solidness of truth: he wants to change our conception of its ground and nature. His transcendental deduction of a necessary enabling role for forms of life does this in two directions: in OC, he deduces a sort of fixity for some empirical propositions:

I would like to regard this certainty [that it's a chair in front of mel, not as something akin to hastiness or superficiality, but as a form of life (358).

Some empirical propositions are held fixed: they are the hinges on which the door can turn (ibid.341); concerning them our eyes are shut to doubt (PI p.244). This thrust of Wittgenstein's thought aims to harden the empirical. On the other hand, much of his writing is aimed at, so to say, softening the non-empirical: but what gets softened is not supposed to be 'the logical 'must"-which Wittgenstein wishes to keep hard-but, again, as with truth in general, our conception of its ground and nature. The new, and prima facie difficult, road we have to take involves saying that while mathematical truth remains independent of whether human beings know it or not' (PI p.226), nevertheless it is not simply true that even if everybody had believed that twice two is five it would still be four-

For what would it be like for everybody to believe that?-Well, I could imagine, for instance, that people had a different calculus, or a technique which we should not call 'calculating'. But would it be wrong? (PI p.226). 
The notion of a form of life is designed to help us steer a course between the empiricism which invites skepticism and the platonism which supposedly imports mystification. ('Don't demand too much [platonism], and don't be afrald that your just demand l'not empiricism and yet realism'] will dwindle into nothing.' RFM VII.19.)

But it is not so clear that Wittgenstein's words entitle him to disembarrass himself of the charge of empiricism. Let us return to the passage from PI Il.xil quoted above. It might well be said that if the notion of a form of life is to perform the grounding task required of it then it must be possible to imagine different forms of life. This does not mean that we have to be able to make good sense of them ('If a lion could talk, we could not understand him', PI p.223), but we must at least be able to conceive of the possibility of such alternatives (e.g., of a lion talking). This claim might look like an empiricist gloss on the notion of a form of life, but Wittgenstein is by no means hostile to it. In fact, the possibility of alternative ways of 'thinking, speaking, inferring, arguing' is connected by Wittgenstein in several places with the anti-platonist thesis, which he wishes to endorse, that logic doesn't 'certainily correspond to the truth' (RFM 1.5; 1.115).

Now PI II.xil exhorts us to "imagine certain very general facts of nature' to be different, and it is natural to read those passages in RFM where Wittgenstein considers alternative forms of mathematical or physical life--such as 1.5 (The Soft Ruler Brigade) and I.149f (The Woodsellers)--as intellectual aids in this endeavour. The Soft Ruler Brigade seem to measure all right, but they do not assent to the arithmetical equations we assent to, such as

(S) $2+2=4$

This is because their rulers expand and contract arbitrarily, so that there will be no one number which 2 added to 2 always yields. Wittgenstein wants the inexorability of (S) for us to be compatible with its falsity for them, and hence with there being no absolute truth which it expresses:

How should we get into conflict with truth, if our footrules were made of very soft rubber instead of wood and steel?-'Well, we shouldn't get to know the correct measurement of the table.-You mean, we should not get, or could not be sure of getting, that measurement which we get with our rigid rulers. (1.5).

But the difficulty is to see how the Soft Ruler Brigade can really be measuring: certainly the scenario Wittgenstein suggests for their practice-a shopkeeper treating different customers differently-would only be possible if they had an independent and rigid standard of measurement (otherwise how would the shopkeeper know he was treating people 
people differently? ${ }^{2}$ ). Surely, if the Brigade are really applying their measurements to workaday projects like putting up shelves or judging long-jump competitions then they will give up their soft rulers for hard ones when we show them the superiority of the latter for their purposes; if they remain incorrigible, doesn't that show that they weren't measuring in the first place? ${ }^{3}$ Insofar as we are prepared to allow the Soft Ruler Brigade their measuring, to that extent (S) seems to lose its hardness. And insofar as we are unwilling to countenance their practice as a bona fide case of measuring, that is because, as we say, (S) is hard.

The Woodsellers (who price wood according to the area it covers on the ground) prompt the same kind of reflection. Wittgenstein assumes that if we come upon them apparently charging a higher price for the same amount of wood when spread over a larger area we can unproblematically translate them as saying things like: 'Yes, now it's a lot of wood and costs more.' (I.150). But really this is not so clear. The same trade-off as we observed above surely applies here too: insofar as we are prepared to regard the Woodsellers as speaking a language, and hence insofar as we are prepared to translate them, we would not translate them as asserting such arrant nonsense as Wittgenstein puts into their mouths.

If we consider such cases from a standpoint initially sympathetic to Wittgenstein, we are in fact pushed in the direction of transcendental rather than substantial conventionalism. ${ }^{4}$ We can feel this attraction working on Wittgenstein too: for although passages like RFM 1.5 and l.149f seem to point unequivocally towards cultural relativism (substantial conventionalism), a passage like the one quoted above from PI p.226 is suggestive of a more transcendental conventionalism or idealism: there Wittgenstein has some difficulty in making sense of a practice in which (S) is regarded as false and which still merits the label 'calculation'. If one starts, as Wittgenstein does, from a broadly conventionalist position, then the temptation to go transcendental becomes very strong when we reflect on 'alternatives' such as measuring with soft rulers. We are inclined to cling onto the (absolute) necessity of $(S)$ and $u$ se it to reject the alternatives. If necessity is ours, then it must be so in a transcendental sense: that is the only way we have a chance of keeping it hard. Hence if a form of life of ours underwrites necessity, it must be our transcendental form of life which does so. What is meant by the phrase 'transcendental form of life' is the form of life of the widest possible community of rational beings: what all such beings who enjoy empirical forms of life have in

${ }^{2}$ Cf. Wright, Wittgenstein on the Foundations of Mathematics (London: Duckworth, 1980), 4.1.

${ }^{3}$ Wright, ibid., 4.5.

'Williams, 'Wittgenstein and Idealism', reprinted in his Moral Luck (Cambridge: CUP, 1981), p.163. 
common. There need be nothing empirical common to all these beings; that is the rationale for calling the form of life they share 'transcendental'.)

We can certainly detect in Wittgenstein's writings an incipient yielding to the temptation to go transcendental; in the next section I shall consider what coherence the notion of a form of life can have when it is read transcendentally. But it is a good idea to be clear how 'substantial' many of Wittgenstein's formulations in this area nevertheless are, for all his disavowal of the empiricist label.5 Consider his treatment of the provenance of necesary truth. At RFM VII. 69 his idea seems to be that an empirical generalization is hardened into a rule. ${ }^{6}$ An example he sometimes uses (e.g., RFM 1.9, VII.69) is that of equivalences between the imperial and metric systems of measurement. We observe a regularity of coinstantiation between, say, $1^{\prime \prime}$ and $2.54 \mathrm{~cm}$, and so we dignify the proposition

\section{(T) $1^{\prime \prime}=2.54 \mathrm{~cm}$}

as a rule, something which becomes part of the river bank and no longer of the stream. The difficulty with this view is that, as we saw earlier, the institution of measurement presupposes a high degree of rigidity in the measuring systems, so that between any two such systems--even supposing they are so isolated from one another that no one ever makes the equivalences--there will be an infinite number of necessary equivalences like $(T)$. In asserting $(T)$, we cannot be establishing anything new, but are merely being faithful to what has been implicitly fixed in the setting up of the systems: $(T)$ is an a posteriori necessary truth.

\section{2}

It appears that if substantial conventionalism is the only other position on offer, we will opt for platonism every time: as far as that choice goes, we will prefer the view that ' $2+2=4$ ' does 'certainly correspond to the truth'. If a form of life is a substantial convention, it is not able to do justice to our modal intuitions. ${ }^{7}$ But perhaps if we read Wittgenstein transcendentally, we may be able to find room for the idea that logical and arithmetical necessity are grounded in a transcendental form of life.

In Kant, transcendental idealism incorporates the doctrine that I-as subject of representational experience-cannot have knowledge of thingsin-themselves, but only of representations, or appearances, of these things. This is because I can only have knowledge of things firstly through intuition, to which I contribute the formal conditions of space and time,

${ }^{5} \mathrm{Cf}$. Bolton, 'Life-form and Idealism' in ed. Vesey, Idealism, Past and Present (Cambridge: CUP, 1982).

${ }^{6}$ And cf. RFM VI.22.

${ }^{7}$ Cf. Cassam, 'Necessity and Externality', Mind vol. XCV. 1986. 
and secondly by subjecting the manifold to the synthetic unity of apperception (i.e., I self-ascribe the disparate elements of the manifold of my experiences. ${ }^{8}$ ) By the time I arrive at a unified experience with objective content, the raw material received through sensibility has been processed in the concept-applying faculty of understanding: the endproduct owes as much to my 'spontaneity' as it does to the world. Kant argues that things-in-themselves lurk behind appearances-they are what appearances are appearances of-but that they are unknowable and, in a sense, inconceivable: we cannot even apply the categories to them. There is considerable tension here between the sense in which things-inthemselves are nevertheless conceivable (we do at least have to believe in their existence) and the sense in which they are not (we can say nothing about them; and that means, of course, that we should not even speak of 'them', for plurality is one of the categories).

Now obviously this tension is avoidable if we just renege on the existence of things-in-themselves; ${ }^{9}$ and it seems to me that we can do this without losing everything of the transcendental idealism of Kant's position. Idealism could remain in the form of a claim to the effect that we can only perceive appearances or representations, but now in the sense of appearances with objective content or things-as-they-appear-to-us (not appearances of anything else); transcendentalism would remain in the standpoint from which this idealistic judgment would be delivered. This would still be the standpoint of critical philosophy: that is, the standpoint concerned with the necessary subjective conditions of all possible experience. ${ }^{10}$ From that standpoint, it would be clear that in order to enjoy experience with objective content, we must take our experience to be of objects existing in space and time, and we must think of them in accordance with ('through') the categories, however we set these up. ${ }^{11}$ The transcendental standpoint would look on experience and the world

${ }^{8}$ See the Critique of Pure Reason(transl. Kemp Smith; London: Macmillan, 1929), B.136. Hereafter all references to Kant will be to this work.

'Strawson's line in The Bounds of Sense (London: Methuen, 1966).

${ }^{10} \mathrm{Cf}$. Walker, Kant (London, Routledge, 1978), ch II. More generally, it is the standpoint concerned with the necessary conditions of the application of concepts to objects (cf.B25). Even more generally, it is concerned with the necessary conditions of the existence of minds in the world. For the extension of the notion of the transcendental to the later Wittgenstein, see Lear, 'Transcendental Anthropology' in McDowell and Pettit edd. Subject, Thought and Context (Oxford: Clarendon, 1986), p.269-70.

${ }^{11}$ Strawson (op.cit., pp.74-82) offers a compelling simplification of Kant's rather baroque structure: object and property survive as the basic categories which must be deployed by any subject enjoying experience of, or thought about, an objective world. 
through an idealist lens; but such idealism would be combinable with the truth of empirical realism-delivered from a standpoint within our experience-that we (normally) perceive objects, not appearances.

Now my purpose in adjusting Kant's transcendental idealism in this way is to render it more analogous to the transcendental idealism we can discern in Wittgenstein's notion of a form of life. I have already alluded to passages in Wittgenstein (such as PI p.226) which invite a transcendental reading. But what exactly is a transcendental form of life? Consider this passage:

If you talk about essence, you are merely noting a convention. But here one would like to retort: there is no greater difference than that between a proposition about the depth of essence and one about-a mere convention. But what if I reply: to the depth that we see in essence there corresponds the deep need for convention $I=\ldots$..there corresponds a deep form of life.] (RFM 1.74. Cf the 'real need' of PI 1.108)

What is this deep need for convention? (What is a deep form of life?) In a famous passage, Stanley Cavell talks of our 'sharing routes of interest and feeling, modes of response, senses of humour and significance and fulfilment... ${ }^{12}$ Jonathan Lear echoes him, talking of our common 'feelings of naturalness', 'perceptions of salience', ${ }^{13}$ and 'our mindedness'. 14 The transcendental idealism in question takes the following form: the necessity of, say,

(S) $2+2=4$

is underwritten by (or in some sense embedded in) our deep form of lifethe only (arithmetical) form of life we can understand, and the form of life which all genuine (arithmetical) forms of life share. The idealism consists in the fact that the truth of (S) is grounded in what we find intelligible ('...the only form of life we can understand...'), in our deep say-so; the transcendentalism enters the picture when we enquire who we deeply are. It will be plausible here to answer that we are whoever count as participators in a form of life, as satisfiers of the (transcendentally deduced) necessary conditions of such participation. And now the important point is that such a deduction will specify certain general conditions of rationality as constitutive of possession of a form of life, and it

${ }^{12}$ Must We Mean What We Say? (New York: Scribner,1969), p. 52.

13'Moral Objectivity' in Brown ed. Objectivity and Cultural Divergence (Cambridge: CUP, 1984), p.148.

14'Leaving The World Alone' J.Phil., vol. LXXIX, 1982, passim. 
Is most likely that such conditions are going to have to include, or entall, willingness to assent to propositions such as (S).

It follows that any statement of the transcendental idealism we arrive at, such as:

(E) the necessity of (S) consists in our being so minded as to assent to it

cannot be allowed to be construed as recording a merely one-way dependence: if the necessity of (S) consists in our being minded in certain ways, still 'our' identity cannot be fixed independently of the necessity of (S). To be one of us you must meet a rationality constraint; to meet that constraint you must think (among other things) that $2+2=4$; it is not (conceptually) possible to be so minded as to think that this equation is false, because such a 'thought' would, as it were, inhibit the constitution of mindedness; hence, $2+2$ must equal 4 . The alternatives are, literally, unthinkable. The 'equation' (E) invited us to ground necessity in our mindedness, but reflection on what our mindedness must amount to (on who we must be), leads us back, circuitously, to (bare, hard) necessity. As Lear well puts it: 15

After we realize that there is (for us) no alternative possibility of being 'other minded'...we seem to come back to our original assertion: $12+2$ must equal 4]. Thus the strange case of the disappearing 'we'...

But the 'we are 80 minded:' does not, according to Lear, entirely disappear:

Our ability to append the 'we are so minded:' represents a permanent possibility of reflective consciousness. (Ibid., p.241).

At this point it is customary to invoke the saying/showing distinction: all we can truthfully say is that $2+2$ must equal 4 . It is not literally true that necessity is grounded in our form of life. If that is a truth, it is one that shows itself in our form of life. ${ }^{16}$ Alternatively, we may call it a transcendental truth, or

...a supposed philosophical truth which, if it is uttered, must be taken to mean an empirical falsehood, or worse...The dependence of mathematics on our decisions, in the only sense in which it obtainsfor clearly there cannot be meant an empirical dependence on

${ }^{15}$ The Disappearing 'We", PASS, vol. LVIII, 1984, p.238.

${ }^{16} \mathrm{Cf}$. McDowell, 'Wittgenstein on Following a Rule', Synthese, vol. 58, 1984, at p.353. 
historical decisions-is something which shows itself in what we are and are not prepared to regard as sense... (Williams, op.cit., p. 163).

This is the doctrine, and even if we are chary of ascribing it to Wittgenstein in anything like such a developed form, there is no question but that his conventionalism is not of a straightforwardly substantial variety, and is in any case unstable in the direction of this sort of transcendental idealism.

I hope it is clear now why I rewrote Kant's transcendental idealism. For the two positions are now thoroughly parallel. The transcendental truths (but empirical falsehoods) are, respectively, that we are inescapably trapped behind our representations; and that we are inescapably ensnared in our form of life. But the respective 'imprisonments' are not really such: there are no objects outside our representations (there are no things-in-themselves); and there is no form of life, no way of being minded, other than ours. The transcendental truths both deny the possibility -so we might put it-of an external perspective on our experience and our practices. Such a perspective would be, by definition, a place from where things-in-themselves, and the real (absolute) facts of the arithmetical matter would be visible. Obviously, if there are no such things, there cannot be a perspective from which they are visible.

The transcendental realist now enters the picture as the person who claims that there is such a standpoint, and, further, that from that standpoint our perceptions and practices are seen to be in order: we really do see things-in-themselves (objects really are the way they appear to us all); our arithmetical concepts are in fact 'absolutely the correct ones'. As McDowell has put it:17

The idea is that the relation of our arithmetical thought and language to the reality it characterizes can be contemplated, not only from the midst of our mathematical practices, but also, so to speak, from sideways on-from a standpoint independent of all human activities and reactions that locate those practices in our 'whirl of organism'.

Transcendental realism is, so Wittgenstein on this interpretation believes, the perennial disease of philosophis aperennis; transcendental idealism is what the therapist prescribes for the sick patient.

The first point to make about this situation is that it is somewhat misleading to present the dialectic as the medical analogy suggests. For it is clear from the way 1 have described the situation that transcendental realism is entirely an artefact of transcendental idealism: it is defined in contrast to the latter. It is then not a disease which transcendental

${ }^{17}$ 'Non-cognitivism and Rule-Following' in edd. Holtzman and Leich, Wittgenstein: To Follow a Rule (London: Routledge, 1981), at p. 150. Cf. also McDowell, art.cit., note 16, at Pp. 351-3. 
idcalism first finds and then cures; rather, the cure evidently creates the disease before curing it. (In a curious way the talk of therapy will then be apposite: therapy is modernity's cure for modernity's diseases.) The point is that no ordinary realistic utterances--such as 'I really do perceive the house as It is in itself or 'It is because the square of 13 really is 169 that we can be brought to find such calculations compelling'-can be interpreted as expressing a transcendental realism (rather than the acceptable empirical look-alike) unless they are placed in a context in which it is clear that the positions they are meant to oppose are transcendental ones, not empirical.

3

But given that the dialectic has this general shape, the following is a natural thought: surely the optimum position is not to fall into transcendental idealism in the first place. For if one avoids it, there is no risk of catching the disease for which it is the cure. Better not to get into the position where one needs therapy at all: one might get hooked. The medical analogue for transcendental idealism should not then be a cure, but a drug. Once one is on a drug, it certainly satisfies a need (which it creates); but it is better to avoid addiction in the first place. Is transcendental idealism avoidable? I think that in the end it is not; but by the time we have laid out for ourselves exactly what doctrine it is, it will have lost its narcotic powers. It will emerge as an ordinary tautology, not the deep philosophical truth it pretends to be. In arriving at the point where we can see this, our tactic will initially be to elucidate the standpoint of critical philosophy from which the transcendental idealist purports to deliver his remarks.

How does this standpoint differ from that of the transcendental realist? It might be thought that there is in fact no difference: both standpoints are 'external' in that they involve stepping back from our 'whirl of organism' and contemplating it from 'sideways on'. If that were right, the transcendental idealist's claim that necessity is dependent on our whirl of organism or form of life, and his rejection of his opponent's standpoint on the grounds that it cannot be coherently occupied, would be disingenuous and self-defeating. ${ }^{18}$ However, what I have already said indicates that this criticism is unfair. The transcendental idealist's standpoint is meant to be critical not in the sense of 'external', but in the sense of being internal and self-conscious. The ability to append the 'we are so minded:' represents, as Lear puts it in the passage I quoted earlier, 'a permanent possibility of reflective consciousness..$^{19}$ It is structurally similar to Descartes' 'cogito' in this respect: a critical conclusion (sum) is

${ }^{18}$ As Cassam claims it is in art.cit., at pp.454-6.

${ }^{19}$ Art.cit., note 15, p. 241. My emphasis. 
reached through self-consciousness (cogito) and without stepping outside an internal first-person perspective. For Descartes, the first-person perspective is singular; for Wittgenstein, it is plural.

In the same way, the Kantian 'I think' must be able to accompany all my representations: from a critical standpoint I realize both that all my representations must be subject to whatever condition enables them to be mine (that I must bring them under a synthetic unity of apperception, and in so doing conceptualize the sensibly given), and that I cannot look behind my representations and perceive things-ln-themselves (i.e., things that are not inherently available to me). This exactly parallels the Wittgensteinian thought (as presented by Lear, McDowell and others) that all our truths, including our necessary truths, are ours; we cannot recognize a truth we cannot recognize, and in our recognizing a truth, it becomes a truth for us. (I cannot see an object I cannot see; and in the possibility of my seeing it it becomes an object for me, ceases to be an object in-itself.)

When the transcendental Idealisms of the Kantian and Wittgensteinian positions are finally set down, they are accordingly seen to be analytic (as Kant acknowledges for his own version, B.138). This was implicit in our earlier observation that we could not gain leverage on the left-hand side of:

(E) The necessity of ' $2+2=4^{\prime}$ consists in our being 80 minded as to assent to it.

via the right-hand side. This fact reduces (E) to a mere tautology. It follows that the transcendental realist must be construed as assenting to a contradiction: he must claim that there are objects-which-we-cannot-see, and that we see them; that there are necessities-which-we-cannot-assentto (because we cannot understand them), and that we assent to them. This brings out the real nature of the external perspective which, it is said, 'we tend, confusedly, to suppose that we occupy'20 when we are impressed by transcendental realism. It is a perspective with an inbuilt contradiction. This realist is at one and the same time drawing a boundary to what we can see or understand, and allowing us to trespass beyond it.

Clearly, if 'we' are defined (at least partly) in terms of those who can understand necessities, there cannot be any avoiding the bare tautology that necessities must be comprehensible by us. But the claims of philosophical interest made on behalf of the tautology, and which are associated with the label 'transcendental idealism', are avoidable. There is, in particular, nothing in the tautology to justify talk of 'whirl of organism' or 'form of life': these phrases seem to promise something substantial in

20McDowell, art.cit., note 17, p. 150. 
the way of foundation or grounding for necessity, but in the event do not deliver it. Cavell writes that:

Human speech and activity, sanity and community, rest upon nothing more, but nothing less, than [forms of life]. It is a vision as simple as it is difficult, and as difficult as it is (and because it is) terrifying. ${ }^{21}$

But we have to reply to this that when the notion of a form of life or whirl of organism is shorn of the empirical content which it seems to carry in Cavell's description; when, that is to say, it is made suitably transcendental, what Cavell says is simply false. And there is no philosophical truth shadowing this falsehood-there is just falsehood. Necessity does not rest on form of life; the dependence is in fact, as we have seen, the other way round. The membership of the transcendental community-the 'we' of the 'we are so minded:'--is collected on the basis of assent to antecedently given necessities (among other things). But there is no reverse dependency: we do not arrive at the necessities by inspecting what we are prepared to assent to. If we did that we should have to rely on an empirical 'we', and then we should have a substantial conventionalism.

In missing the tautological character of transcendental idealism, proponents of it have consequently also misrepresented their transcendentally realistic opponent. McDowell ascribes to him

the idea that provable correctness characterizes exercises of reasons in which it is, as it were, automatically compelling, without dependence on our partially shared 'whirl of organism:.22

But the dependence which McDowell wants is, as we have seen, simply not there to be had. Rather, the dependence is the other way round: what holds our whirl of organism together is (among other things) the automatic compulsoriness of mathematical proof and necessity. Pase Cavell and McDowell, there is no vertigo to be felt (or only by an empirical idealist); no feeling of human organism being all that keeps the rationality show on the road. Quite the reverse: the old picture of the mind engaging with universalist rails has not in fact been supplanted by our transcendental idealism, but merely supplemented, and supplemented by a tautology. We have not escaped, after all, from the crystalline purity-the sublimityof the logic of our language (PI 1.89, 1.105-8). To suppose that the sheer tautology which transcendental idealism serves us up takes us off the ice onto the rough ground (ibid., 1.1.07) is an illusion: when we do logic we are on ice. But so far from existing apart from us in inhuman alienation, the

${ }^{21}$ Cavell, O. cit., p. 52.

2McDowell, o. cit., p. 152. 
crystalline purity of logic is the very thing that personalizes us: it is precisely our (or anyone's) ability to make contact with the normative rails along which rules inexorably run that constitutes us (or anyone) as persons (rational beings) at all.

The platonist's claim is that universals have, so to speak, a life of their own. What is meant by this is that the rules which universals and their inter-relations embody possess a compulsoriness or normativity to which we make no contribution, and which is simply ineluctable. It is quite natural to represent such rules as rails laid out independently of the say-so of the track-users; this picture is not misleading 80 long as it is borne in mind that the rails are normative, not mechanical. That there is no mechanical surrogate for normativity is something which Wittgenstein is at some pains to show; but there is no warrant for accusing the platonist of offering a mechanistic account of rule-following. The most which the platonist wants is the automatic compulsoriness of rules: he is by no means committed to a mechanistic view of how they compel. ${ }^{23}$

${ }^{23}$ Wittgenstein is followed in his slur on the platonist by many of his commentators including, recently, Pears (The False Prison; Oxford: Clarendon, 1987). See especially pp.9-11, 59-60. The mistake is made in the following passage, for example:

[The platonist's rails] would be no use, because the speaker's mind would have to contain something-an image perhaps, or a formulawhich would be both strictly contemporary and also a self-contained, unambiguous representation of the infinite line dividing positive from negative instances; which is impossible. (pp.59-80)

But of course the platonist's rails are not designed to be of use; they are intended to give expression to the independent compulsoriness of rules-to the fact that nothing in the way of what counts as obeying or disobeying a rule is up to us. And that is correct.

The view that understanding consists in the possession of a formula (considered as a syntactic object) or a mental image-a view which comes under heavy and merited attack in the pages of PI-is not a platonist thesis. To be in a state of understanding is to engage with the platonist's rails in the sense of being in an infinitistic state: that state cannot, as Wittgenstein cogently argues, be identified with a merely occurrent mental state, such as the possession of an image or the recitation to oneself of a formula. This is because a merely occurrent state--conceived simultaneously as infinitisitic-would have to drive its applications mechanically or at least causally; but there is no causal surrogate for the normative, and normativity is precisely what characterizes the way states of understanding relate to their applications. The attempt by Wittgenstein's interlocutor to bridge the gap between the mechanical and the normative only produces 
the fantastic and unlovely notion of the supermechanical. But platonism is not fantastic: that would be for normativity itself to be fantastic. Of course Wittgenstein does not wish to be saddled with this intolerable conclusion; but the attempt to incorporate a contribution from the rulefollowers into the nature of rules cannot fail to foist it on him. It is just as misguided on his part as the attempt, which he rightly castigates, to mechanize the normative.

Perhaps I should say a bit more about the incoherence of the notion of supermechanism. (Some of the relevant passages in Wittgenstein are PI 1.192ff, RFM 1.118-30, Z 296.) The point is that if a rule determined its applications causally, it would be possible to build a machine which was guaranteed to follow a rule. But it is not so possible, because a machine may always, as we say, malfunction, whereas it cannot fail to behave mechanistically or causally. We are tempted at this point to hypothesize an ideally rigid machine, a machine which can only move in such-andsuch ways, and so is guaranteed to follow a rule. But a machine which cannot malfunction is a philosophical fiction. You cannot get to the normative by 'hardening' the mechanical (by positing ideal processes which are still mechanical). The normative is not the supermechanical; a rule-follower is not a supermachine. Rather, the normative is different in kind from the causal or mechanical: the connection between a rule and its applications is constitutive, or logical, and not causal (Wittgenstein is inclined, misleadingly, to say that it is a matter of grammar. See, e.g., RFM 1.128). There is an excellent discussion of the failure of the mechanical model of rule-following in Kripke's Wittgenstein on Rules and Private Language (Oxford: Blackwell, 1982), at pp.22-30. But the consequence of rejecting the mechanistic model of rule-following is not, as Kripke supposes, an unavoidable skepticism about our ability to follow rules; on the contrary, it is to replace an erroneous way of regarding rule-following with a just perception of it:

How queer: it looks as if a physical (mechanical) form of guidance could misfire and let in something unforeseen, but not a rule ( $Z$ 296).

The queerness alluded to here derives from supposing that rule-following is a mechanical process; jettison that assumption and the queerness vanishes. Machines and rules will then be seen to 'guide' in quite different senses (cf. PI 1.195). (See McDowell, art.cit., note 16, for a good analysis of what is wrong with Kripke's 'skeptical paradox' and 'skeptical solution'.)

Nothing in this discussion prejudges the question whether a grasp of the phenomenon of normativity can be realized in a causal system. This is a quite separate issue. Granted that the ability to follow a rule does not 
We are faced, after all, with a ready-made world. We have seen that an acceptable transcendental idealism can do no more than supplement an otherwise healthy platonism with the truism that rules compel us $(=$ all those compelled by the rules). No platonist would wish to demur at such an appendix to his position. But while we cannot dissent from the tautology, we can deny it the significance which writers, following Wittgenstein, have wanted to build into it. And we can reinstate realism about objects and necessity without falling into transcendental realism. This doctrine, revealed as a contradiction, also loses philosophical interest; and it becomes extremely unlikely that any philosopher has ever assented to it.

The notion of a transcendental form of life has thus been emptied of content: there is nothing to set against it; we cannot contrast another form of life with it to get some idea of what it is not. And in any case it cannot play the supportive role it was suborned for. In terms of the saying/showing distinction, we can say that there is no transcendental point of view which we as the transcendental community-to whom certain transcendental truths (but empirical falsehoods) make themselves manifest-inhabit. This reflects the tautological nature of transcendental idealism. For there is nothing unsayable about a tautology: the transcendental truth that the world we live in is our world is not empirically false and hence at best showable but not sayable. It is not an empirical statement at all: the 'our' in it is transcendental, and the statement as a whole is tautological because our world just is, when all's said, the world. ${ }^{24}$

consist in the possession of a set of causal dispositions (to any degree of complexity); nevertheless it seems quite plausible that the notion of a rule is potentially graspable by any machine complex enough to possess second-order dispositions. Such a machine is at least in a position (given suitable further complexity) to grasp the notion of the correct application of a rule; of course it is not guaranteed against breakdown, but then no rule-follower ever is. What it is to follow a rule is not a mechanical matter; but machines can follow rules: they can do so if (among other things) they can review critically their own functional dispositions. (Of course those reviewing dispositions can break down: machines can 'go mad.')

${ }^{24} I$ have been helped in writing this paper by conversations with John McDowell and David Wiggins. 